\title{
Left Ventricular Measurements in Black Sub-Saharan Africans and White Maghreb
}

\author{
Bernard Phanzu Kianu ${ }^{1 *}$, Charifa Annis ${ }^{2}$, Sidibe Moussa ${ }^{2}$, Eleuthère Vita Kintoki', \\ Karimi El Saloua ${ }^{2}$, Dounia Benzaroual'2, Mustapha El Hattaoui ${ }^{2}$, Benjamin Longo-Mbenza ${ }^{3}$, \\ Jena-Réné M'buyamba Kabangu' 1
}

${ }^{1}$ Cardiology Unit, University Hospital of Kinshasa, University of Kinshasa, Kinshasa, Congo

${ }^{2}$ Cardiology Unit, CHU Mohammed VI, Cady Ayyad University, Marrakech, Morocco

${ }^{3}$ Faculty of Health Sciences, Walter Sisulu University, Mthatha, South Africa

Email: *doctorkianu@gmail.com

How to cite this paper: Kianu, B.P., Annis, C., Moussa, S., Kintoki, E.V., El Saloua, K., Benzaroual, D., El Hattaoui, M., Longo-Mbenza, B., Kabangu M'buyamba, J.-R. (2017) Left Ventricular Measurements in Black Sub-Saharan Africans and White Maghreb. World Journal of Cardiovascular Diseases, 7, 195-206.

https://doi.org/10.4236/wjcd.2017.76018

Received: April 24, 2017

Accepted: June 24, 2017

Published: June 27, 2017

Copyright $\odot 2017$ by authors and Scientific Research Publishing Inc. This work is licensed under the Creative Commons Attribution International License (CC BY 4.0).

http://creativecommons.org/licenses/by/4.0/

\section{(c) (i) Open Access}

\begin{abstract}
Background: Evidence that blacks have greater left ventricular mass (LVM) than whites has been demonstrated by large population-based American studies. However, to our knowledge, there is no study to date comparing LVM in Black Sub-Saharan Africans (BSSA) and the Maghreb white population. We compared LVM measured echocardiographically in asymptomatic BSSA and Maghreb. Methods and Results: A total of 100 asymptomatic BSSA and 189 Maghreb, (18 to 55 years old), underwent resting two-dimensional transthoracic echocardiography. LVM and geometry were assessed according to the 2015 American Society of Echocardiography and the European Association of Cardiovascular Imaging updated guidelines for cardiac chamber quantification. Crude or indexed LVM to body surface area or height ${ }^{2.7}$ was similar in BSSA and in Maghreb (132.7 \pm 37.0 vs. $134.2 \pm 35.7 \mathrm{~g} ; 73.1 \pm 17.8$ vs. $72.9 \pm 16.2 \mathrm{~g} / \mathrm{m}^{2}$; $32.1 \pm 9.8$ vs. $\left.33.6 \pm 9.5 \mathrm{~g} / \mathrm{m}^{2.7}\right)$. However, the left ventricular posterior wall was thicker in BSSA. Patterns of left ventricular geometry (normal, concentric remodeling, or concentric or eccentric hypertrophy) were equally distributed among the two ethnic groups. Conclusions: Left ventricular posterior wall thickness but not LVM is greater in BSSA than in Maghreb.
\end{abstract}

\section{Keywords}

Left Ventricular Mass, Ethnicity, White Maghreb, Black Sub-Saharan Africa

\section{Introduction}

Blacks are generally more susceptible to cardiovascular disease than whites [1]. Major efforts are underway to reduce disparities in health outcomes between 
blacks and whites [2]. Left ventricular mass (LVM) reflects hemodynamic, neurohormonal, humoral, metabolic, and genetic disorders [3] [4] [5]. Environmental factors also influence LVM [6] [7]. Left ventricular hypertrophy (LVH) is an adaptive response allowing a normal ejection fraction despite abnormal pressure and/or volume load [4] [8] [9]. However, recent studies over many years [10] [11] [12] [13] have shown the importance of LVH as a subclinical marker of cardiovascular disease. Indeed, LVH is considered a cardiovascular risk factor (CVRF) [13] [14]. Its value in predicting cardiovascular events has been widely demonstrated in subjects with [10] [13] and without coronary artery disease [15] or heart failure [16]. LVM correlates closely with the incidence of heart failure, stroke, coronary disease [17], and overall mortality [18]. A reduced incidence of cardiovascular events is also noted after lifestyle modification and/or pharmacological treatment to reduce LVM [16] [19].

LVM is determined by heritable genetic factors [20] as well as environmental factors, the latter including diet and physical activity. It was recently demonstrated that a diet low in animal fat and high in vegetables, fruit, and monounsaturated fatty acids is associated with a low LVM [21] [22] and low cardiovascular risk. Physical activity reduces LVM [23], while physical inactivity is associated with increased LVM in whites but not in blacks [7].

The evidence that blacks have a greater LVM than whites do is almost indisputable [24]. LVH is more prevalent in blacks than whites [25] and is also more closely linked to the risk of cardiovascular mortality in African Americans than it is in whites [26]. Disparities in LVM and LVH are likely to explain a large part of the increased cardiovascular mortality in blacks [25].

Differences in LVM between African Americans and white Americans are widely described in the literature. However, to our knowledge, there is no study to date comparing LVM in black sub-Saharan Africans (BSSA) with that of the Maghreb, a white-skinned North African people of Arab-Berber origin. BSSA living in Africa certainly have common ancestry with African Americans, but this relationship is very remote and their lifestyles are very different. Similarly, the Maghreb, although white skinned, have historical and cultural roots completely different from the primarily European ethnic heritage of white Americans. Thus, the results from studies comparing African Americans with white Americans cannot be extrapolated to these two African ethnic groups. The MAG-SALVAGES (MAGhreb and Sub-Saharan African Left-Ventricul ArGEometry Study) aimed to compare the LVM of Maghreb with that of BSSA.

\section{Methods}

\subsection{Study Design}

\subsubsection{Study Population and Settings}

The MAG-SALVAGES is a population-based survey conducted in Marrakech, Morocco, from November 2015 to January 2016. The Kingdom of Morocco is a Northwest African country where the quality of university education has improved rapidly in recent years. This makes it a preferred destination for sub-Sa- 
haran students, especially Francophone sub-Saharans. This study compared a BSSA student population living in Marrakech with a Maghreb student population living the same city.

\subsubsection{Recruitment Strategy}

Investigators: The investigation team consisted of senior residents of the Cardiology Unit of Cady Ayyad University. The principal investigators (BKP and CA) introduced the study, explained the goals, described how the study was to be performed, and described the responsibilities of each investigator. The principal investigators attended staff meetings to discuss and answer any questions the investigator team had. A pre-test session was conducted asking a dozen students to evaluate the questionnaire, to test the appropriateness of the data collection sheet, and to assess the ability of the investigators to apply the protocol correctly.

Study participants: The CESAM (Confédération d'Etudiants et Stagiaires Africains de Marrakech) that is a cultural association encompassing all BSSA students in Marrakech, provided us with the names and addresses of BSSA students. Recruitment of Maghreb students was facilitated by the Secretary General of the Cady Ayyad University Students Office. Students were randomly chosen and invited to participate in the study.

Eligibility criteria: The subjects recruited for the MAG-SALVAGES were asymptomatic students aged 18 years or older, regardless of their level of study (undergraduate, graduate, post-graduate, or doctoral). Participants with significant valvulopathy, who had poor echogenicity to the extent that echocardiographic parameters could not be measured, or who did not complete the planned investigations were excluded.

\subsection{Data Collection}

Left ventricular measurements were taken according to the 2015 American Society of Echocardiography and the European Association of Cardiovascular Imaging updated guidelines for cardiac chamber quantification [27], using an HD 15 Sonos 5500 (Phillips Medical Systems, Andover, MA, USA) ultrasound system equipped with $2.5,3.5$, and $5.0 \mathrm{MHz}$ transducers. Three measurements were taken for each variable, with the mean value used in analysis. Images were stored for subsequent validation by a team of three skilled training specialists of the CHU Mohammed VI echocardiography laboratory. Two-dimensionally guided M-mode echocardiography was performed on a parasternal long-axis view. Interventricular septum (IVS) thickness in diastole (IVSd) in $\mathrm{mm}$, left ventricular posterior wall (PW) thickness in diastole (LVPWd) in mm, and left ventricular end-diastolic diameter (LVEDd) in $\mathrm{mm}$ were measured at end-diastole at a level just below the mitral valve leaflets. Simultaneous ECG was used to correlate measurements with the cardiac cycle. Diastolic wall thickness was measured at the onset of the QRS wave. LVM was calculated according to the American Society of Echocardiography simplified cubed equation linear method using the following equation: LVM (grams) $=0.8 \times 1.04 \times[($ LVEDd + IVSd + LVPWd $) 3-$ 
(LVEDd)3] +0.6 g. LVM was indexed by BSA and by height ${ }^{2.7}$. LVM was considered normal when $\leq 115 \mathrm{~g} / \mathrm{m}^{2}$ or $\leq 48 \mathrm{~g} / \mathrm{m}^{2.7}$ in males and $\leq 95 \mathrm{~g} / \mathrm{m}^{2}$ or $\leq 44 \mathrm{~g} / \mathrm{m}^{2.7}$ in females. LVH was defined as LVM exceeding those values. The relative wall thickness (RWT) of the left ventricle (LV) was calculated as $(2 \times$ LVPWd)/ LVEDd. LV geometric patterns were defined as follows: normal geometry (normal LVM and RWT $\leq 0.42$ ), concentric remodeling (normal LVM and RWT > 0.42 ), concentric hypertrophy (LVH and RWT $>0.42$ ), and eccentric hypertrophy ( $\mathrm{LVH}$ and RWT $\leq 0.42$ ).

To analyze LV systolic function, the ejection fraction (stroke volume/diastolic volume $\times 100$ ), percentage of LV systolic shortening (\%) ([diastolic diameter systolic diameter]/diastolic diameter $\times 100$ ] and cardiac output (stroke volume $\times$ heart rate) were calculated. Stroke volume was calculated as $2 \pi \mathrm{D} / 4 \times$ velocity time integral, where $\mathrm{D}$ is the diameter of the aortic annulus measured in the left parasternal long-axis view at mid-systole from inner edge to inner edge.

The presence or absence of valve disease was detected by visual assessment in 2D and color Doppler in the left parasternal long-axis and apical four-chamber views.

\section{Statistics}

Details about the other data collection strategy (demographic characteristics, lifestyle, personal medical history, physical measurements, Vital signs, and ECG Measurements and interpretation) have been described elsewhere [28] [29].

\subsection{Statistics}

After encoding and validation, the data were entered in a computer using Epi-InfoTM statistical software, version 7.1.2.0 (Atlanta, USA)

(https://www.cdc.gov/epiinfo/index.html). Results for each BSSA were compared with two Maghreb subjects matched for age ( \pm 1 year) and sex in order to overcome the influence of these variables on LVM. Continuous variables are expressed as means and categorical variables as percentages. In order to compare means in independent samples, Student's $t$ test or the Mann-Whitney test was used. Comparison of the means of three or more groups was performed with analysis of variance. The Tukey test for multiple comparisons was used to distinguish the different groups. For variables not fitting a normal distribution, the Kruskal-Wallis analysis of variance and the corresponding test of multiple comparisons were used. Pearson's correlation coefficient ( $r$ ) was used to assess any significant association between two continuous variables. To compare proportions, the chi-square test or Fisher exact test was used. Frequency distributions of LVM dichotomized by ethnicity were constructed. Comparisons were made between BSSA and Maghreb for all parameters. Similar analyses stratified by gender were performed. When differences were observed on univariate analysis, the effect of potential confounders was studied by adjustment with multivariate linear regression. A significance level of 5\% was adopted. IBM SPSS version 21 (http://www.ibm.com/support/knowledgecenter/SSLVMB_21.0.0) was used for statistical calculations. 


\subsection{Ethics and Consent}

This research was conducted in strict compliance with the recommendations of the Helsinki Declaration III. All respondents were briefed on the conclusions drawn from their investigations. Approval was obtained from the ethics committee of Cady Ayyad University. Each participant provided written informed consent.

\section{Results}

Table 1 displays comparatively the demographic and lifestyle characteristics of SSA and Maghreb. Overall, Maghreb were more active and consumed more fruits and vegetables than the BSSA did. The two different ethnic groups did not differ in age, gender, physical activity and cigarette smoking.

Table 2 displays the physical variables and cardiovascular risk factors of the study population as a whole and stratified according to the ethnicity. Maghreb had greater parameters of obesity, including BMI, WC, HC, WHR and fat mass.

Table 1. Characteristics of the study population as a whole and stratified according to ethnicity.

\begin{tabular}{|c|c|c|c|c|}
\hline Variables & $\begin{array}{l}\text { All participants } \\
\qquad \mathrm{n}=289\end{array}$ & $\begin{array}{c}\text { BSSA } \\
\mathrm{n}=100\end{array}$ & $\begin{array}{c}\text { Maghreb } \\
\mathrm{n}=189\end{array}$ & $\mathrm{p}$ \\
\hline \multicolumn{5}{|l|}{ Demographic characteristics } \\
\hline Age, years & $29.8 \pm 11.2$ & $28.5 \pm 10.7$ & $30.4 \pm 11.5$ & 0.171 \\
\hline Gender & & & & 0.121 \\
\hline Male, n (\%) & $173(59.9)$ & $65(65.0)$ & $108(57.1)$ & \\
\hline Female, n (\%) & $116(40.1)$ & $35(35.0)$ & $81(42.9)$ & \\
\hline Place of birth & & & & $<0,0001$ \\
\hline SSA, n (\%) & $99(34.4)$ & $98(98.0)$ & $1(0,5)$ & \\
\hline Maghreb, n (\%) & $189(65.6)$ & $2(2.0)$ & $187(99.5)$ & \\
\hline \multicolumn{5}{|l|}{ Lifestyle characteristics } \\
\hline \multicolumn{5}{|l|}{ Regular consumption of } \\
\hline Fruits, n (\%) & $162(56.1)$ & $39(39.0)$ & $123(65.1)$ & $<0.0001$ \\
\hline Vegetables, n (\%) & $225(77.9)$ & $68(68.0)$ & $157(83.1)$ & 0.005 \\
\hline Fats, $\mathrm{n}(\%)$ & $276(95.3)$ & $93(93.0)$ & $183(96.8)$ & 0.201 \\
\hline \multicolumn{5}{|l|}{ Smoking/Alcohol } \\
\hline Current smoker, n (\%) & $18(6.2)$ & $6(6.0)$ & $12(6.3)$ & 0.564 \\
\hline Excessive drinker, n (\%) & $8(2.8)$ & $2(2.0)$ & $6(3.2)$ & 0.436 \\
\hline \multicolumn{5}{|l|}{ Physical activity } \\
\hline Active, n (\%) & $203(70.2)$ & $61(61.0)$ & $142(75.1)$ & 0.015 \\
\hline Inactive, $\mathrm{n}(\%)$ & $86(29.8)$ & $39(39.0)$ & $47(24.9)$ & 0.018 \\
\hline sedentary, n (\%) & $87(30.1)$ & $19(29.0)$ & $58(30.7)$ & 0.801 \\
\hline
\end{tabular}

BSSA: Black Sub-Saharan African, SSA: Sub-Saharan Africa. 
Table 2. Physical variables and cardiovascular risk factors of the study population as a whole and stratified according to the ethnicity.

\begin{tabular}{|c|c|c|c|c|}
\hline Variables & All participants & BSSA & Maghreb & $\mathrm{p}$ \\
\hline Weight, kg & $73.3 \pm 14.9$ & $72.2 \pm 13.2$ & $73.9 \pm 15.8$ & 0.368 \\
\hline Height, $\mathrm{cm}$ & $168.1 \pm 9.8$ & $169.7 \pm 8.5$ & $167.2 \pm 10.3$ & 0.039 \\
\hline BMI, $\mathrm{kg} / \mathrm{m}^{2}$ & $25.9 \pm 5.5$ & $24.5 \pm 4.6$ & $26.7 \pm 5.7$ & 0.001 \\
\hline $\mathrm{WC}, \mathrm{cm}$ & $86.3 \pm 14.5$ & $82.4 \pm 15.2$ & $88.4 \pm 13.7$ & 0.001 \\
\hline $\mathrm{HC}, \mathrm{cm}$ & $99.6 \pm 10.6$ & $96.3 \pm 9.4$ & $101.4 \pm 10.7$ & $<0.0001$ \\
\hline WHR, cm & $0.87 \pm 0.12$ & $0.86 \pm 0.17$ & $0.87 \pm 0.08$ & 0.399 \\
\hline $\mathrm{WHeR}, \mathrm{cm}$ & $0.45 \pm 0.09$ & $0.41 \pm 0.06$ & $0.50 \pm 0.08$ & 0.031 \\
\hline $\mathrm{SBP}, \mathrm{mmHg}$ & $119.4 \pm 15.1$ & $116.6 \pm 14.6$ & $120.9 \pm 15.2$ & 0.020 \\
\hline $\mathrm{DBP}, \mathrm{mmHg}$ & $77.2 \pm 10.1$ & $76.4 \pm 10.4$ & $77.6 \pm 10.0$ & 0.316 \\
\hline $\mathrm{PP}, \mathrm{mmHg}$ & $42.2 \pm 11.7$ & $40.2 \pm 11.1$ & $43.3 \pm 11.9$ & 0.035 \\
\hline $\mathrm{MBP}, \mathrm{mmHg}$ & $91.3 \pm 10.7$ & $89.8 \pm 10.7$ & $92.1 \pm 10.6$ & 0.084 \\
\hline HR, bpm & $72.7 \pm 12.9$ & $71.5 \pm 12.0$ & $73.4 \pm 13.4$ & 0.227 \\
\hline Fat mass, $\%$ & $20.9 \pm 12.2$ & $17.4 \pm 9.2$ & $22.8 \pm 13.1$ & $<0.0001$ \\
\hline Lean mass, $\%$ & $29.6 \pm 4.5$ & $29.6 \pm 4.3$ & $29.6 \pm 4.7$ & 0.972 \\
\hline \multicolumn{5}{|l|}{ CVRF } \\
\hline HTN, n (\%) & $9(3.1)$ & $3(3.0)$ & $6(3.2)$ & 0.893 \\
\hline DM1, n (\%) & $1(0.3)$ & $0(0.0)$ & $1(0.5)$ & 0.654 \\
\hline DM2, n (\%) & $5(1.7)$ & $1(1.0)$ & $4(2.1)$ & 0.441 \\
\hline Total obesity, n (\%) & $63(21.8)$ & $15(15.0)$ & $48(25.4)$ & $<0.0001$ \\
\hline Abdominal obesity, n (\%) & $64(22.1)$ & $14(14.0)$ & $50(26.5)$ & 0.013 \\
\hline
\end{tabular}

BSSA: Black Sub-Saharan African, BMI: body mass index, WC: waist circumference, HC: hip circumference, WHC: waist-to-hip ratio, WHeR = waist-to-height ratio, SBP: systolic blood pressure, DBP: diastolic blood pressure, PP: pulse pressure, MBP: mean blood pressure, HR: heart rate, FM: fat mass, CVRF: cardiovascular risk factor, DM1: type 1 diabetes mellitus, DS2: type 2 diabetes mellitus.

They had also a higher prevalence of both total and abdominal obesity. When comparing the parameters of blood pressure, Maghreb had higher SBP, while the other parameters including DBP, MBP and PP did not differ between the two ethnic groups. The prevalence of hypertension and diabetes mellitus was similar in the two ethnic groups.

Electrocardiographic and echocardiographic characteristics of the two ethnic groups are shown in Table 3. QRS and QTc duration were the only ECG parameters that differed between the two populations, with a significantly longer average duration among Maghreb. The same table shows a significantly higher LVEDd among Maghreb than among BSSA, but this difference disappeared when indexed to BSA. LVPWd was significantly greater among BSSA than among Maghreb. This difference persisted after adjustment for confounding factors (BMI, WC, HR, and fat mass). The differences observed for all other echocardiographic parameters were not statistically significant, including LVM for which the means of the two groups were similar regardless of the mode of Indexing. 
Table 3. Electrocardiographic and echocardiographic characteristics.

\begin{tabular}{ccccc}
\hline Variable & All participants & BSSA & Maghreb & $\mathrm{p}$ \\
\hline PR, msec & $145.9 \pm 27.5$ & $146.2 \pm 23.2$ & $145.8 \pm 29.6$ & 0.901 \\
QRS, msec & $94.7 \pm 23.2$ & $90.2 \pm 20.5$ & $97.1 \pm 24.2$ & 0.016 \\
QTc duration, msec & $401.5 \pm 40.1$ & $394.1 \pm 33.6$ & $405.4 \pm 42.7$ & 0.023 \\
LVEDd, mm & $48.2 \pm 4.8$ & $47.1 \pm 5.1$ & $48.9 \pm 4.6$ & 0.004 \\
LVEDd/BS, mm/m ${ }^{2}$ & $25.6 \pm 6.0$ & $26.2 \pm 2.9$ & $25.3 \pm 7.2$ & 0.218 \\
LVEDs, mm & $30.3 \pm 4.1$ & $29.9 \pm 4.2$ & $30.6 \pm 4.1$ & 0.185 \\
LVPWd, mm & $8.1 \pm 1.3$ & $8.3 \pm 1.2$ & $7.9 \pm 1.3$ & 0.011 \\
IVSd, mm & $8.2 \pm 1.3$ & $8.4 \pm 1.3$ & $8.2 \pm 1.3$ & 0.187 \\
LVM, g & $133.7 \pm 36.1$ & $132.7 \pm 37.0$ & $134.2 \pm 35.7$ & 0.726 \\
LVM/height ${ }^{2.7}$ & $33.1 \pm 9.6$ & $32.1 \pm 9.8$ & $33.6 \pm 9.5$ & 0.185 \\
LVM/BS, mg/cm & $73.0 \pm 16.8$ & $73.1 \pm 17.8$ & $72.9 \pm 16.2$ & 0.922 \\
LVEF, \% & $65.7 \pm 7.7$ & $65.3 \pm 9.4$ & $65.9 \pm 6.6$ & 0.526 \\
\hline
\end{tabular}

BSSA: Black Sub-Saharan African. PR: PR interval. QRS: QRS duration. QTc: heart rate-corrected QT. LVEDd: left ventricular end-diastolic diameter. LVEDd/BS: left ventricular end-diastolic diameter indexed for body surface area. LVEDs: left ventricular end-systolic diameter. LVPWd: left ventricular posterior wall thickness in diastole. IVSd: Interventricular septum thickness in diastole. LVM: left ventricular mass crude. LVM/height ${ }^{2.7}$ : left ventricular mass indexed for height 2.7. LVM/BS: left ventricular mass indexed for body surface area. LVEF: left ventricular ejection fraction.

\section{Discussion}

This is, to the best of our knowledge, the first population-based study to evaluate ethnic disparities in LVM on the African continent. The main finding was the lack of difference in LVM between Maghreb and BSSA, two ethnic groups with quite different historical origins, dietary habits, physical activity, and physical habitus.

This comparison of LVM in BSSA and Maghreb ideally would comprise samples randomly selected from these ethnic groups. Unfortunately, it is difficult to obtain a representative sample of both populations in the strict epidemiologic sense for obvious reasons of feasibility and budget. For this study, we assumed that a BSSA community and a Maghreb community living in Morocco were representative of the populations from which they originated. CESAM includes BSSA students from the majority of sub-Saharan countries, incuding Mali, Democratic Republic of the Congo, Congo-Brazzaville, Central African Republic, Cameroon, Togo, Chad, Zimbabwe, Tanzania, Angola, Sudan, Somalia, Madagascar, Mauritius, Comoros, Senegal, Nigeria, and Mauritania [28] [29]. Random sampling in this community can be therefore considered representative of the sub-Saharan population.

LVM was evaluated using resting two-dimensional transthoracic echocardiography, long considered the gold standard for measurement of LVM. Magnetic resonance imaging is more accurate than echocardiography [30], so it might be expected to supplant echocardiography. Indeed, the recommended formula for echocardiographic estimation of LVM uses linear measurements based on the 
assumption that the LV is a prolate ellipsoid of revolution, whereas cardiac magnetic resonance models of the LV free of geometric assumptions or acoustic window dependency, yielding better accuracy and reproducibility. However, echocardiography remains the most commonly used imaging modality due to its widespread availability and lower cost. Because it remains the clinical standard, this study used transthoracic echocardiography to measure LVM.

The results of this study contrast with the vast majority of studies that have investigated this issue and which have reported a greater LVM and prevalence of LVH in blacks than in whites [25] [31]-[37].

An old meta-analysis by Devereux et al. reviewed nine previous studies looking at ethnic disparities in LVM and authors reported that LV wall thickness but not LVM was consistently greater in blacks than in whites. That analysis recalls the often forgotten fact that thick walls are not the same as LVH, even LV wall thickness is commonly considered a surrogate for LVM, so that wall thickening is equated with LVH. In reality, this overlooks the relationship between LV volume and wall thickness. The 2015 ASE guidelines for chamber quantification [29] describe a normal LV wall thickness (IVS or PW) as $0.6-1.0 \mathrm{~cm}$ for males and $0.6-0.9 \mathrm{~cm}$ for females. An increased wall thickness may be suggestive of $\mathrm{LVH}$, but as an isolated number it gives no information about LVM or LV modeling. Indeed, LVM is estimated by calculating the total heart volume (epicardial volume) minus the volume of blood in the cavity (endocardial volume), resulting in myocardial volume, and then multiplying by the specific gravity of tissue (1.05). In our study, BSSA had significantly thicker LVPWd than Maghreb, but the LVM did not differ between the two ethnic groups.

LVM is determined by heritable genetic [12] and environmental factors. The historical and ethnic origins of the participants of this study both suggest genetic differences between these two populations. The impact of genetics is often cited to explain ethnic disparities in LVM. But phenotypic manifestations are related to both genetic and environmental factors. In this study, the main environmental factors that may interact with genetics to affect LVM were unevenly distributed between the ethnic groups. The BSSA were less obese and more physically inactive than the Maghreb, while the opposite was observed in the American population, where blacks were more obese and had a higher LVM than whites. It has been postulated that the higher prevalence of obesity in African American populations explains the greater prevalence of LVH, but Mark et al. showed that this ethnic disparity persisted after adjustment for body composition [16].

\section{Limitations of the Study}

A limitation of this study is that BSSA participants were drawn from a migrant population, whose lifestyle therefore does not necessarily reflect that of their country of origin.

\section{Conclusion}

BSSA had thicker LVPWd than the Maghreb, while the two ethnic groups had 
similar LVM. Genetic and environmental factors that influence LVM differ from one ethnic group to another and from one person to another both in nature and magnitude. This probably explains both the differences and similarities in LVM between two ethnic groups, as well as between two individuals.

\section{Acknowledgements}

The authors gratefully acknowledge Mr. CISSE Kalilou Papa, president of the CESAM, and Mr. Sharif Zian, Secretary General of the Office of the Cady Ayyad University Students, for kindly facilitating the recruitment and mobilization of participants. The authors also express gratitude to the following people for their active and voluntary participation in the survey: Wetchi Adolphe, Louis Kyungu, Issa Imbongo, Harouna Mbaka and Djuma Nkubokoso. Special thanks is sent to the PAC Association (Physicians Across Continents) and to its Secretary General, Dr. Saad Ali Al-Qarni, for their partnership with the Faculty of Medicine of University of Kinshasa and for funding Dr Kianu Phanzu Bernard's Training in the Service of Cardiology of CHU Mohammed VI of Marrakech.

\section{References}

[1] Wond, N.D. (2014) Epidemiological Studies of CHD and the Evolution of Preventive Cardiology. Nature Reviews Cardiology, 11, 276-289.

https://doi.org/10.1038/nrcardio.2014.26

[2] US Department of Health and Human Services (2000) Healthy People 2010: Understanding and Improving health and Objectives for Improving Health. Vol. 2. US Government Printing Office, Washington DC, United States.

[3] Meyers, K.J., Mosley, T.H., Fox, E., Boerwinkle, E., Arnett, D.K., Devereux, R.B. and Kardia, S.L. (2007) Genetic Variations Associated with Echocardiographic Left Ventricular Traits in Hypertensive Blacks. Hypertension, 49, 992-999. https://doi.org/10.1161/HYPERTENSIONAHA.106.081265

[4] Devereux, R.B., Savage, D.D., Sachs, I. and Laragh, J.H. (1983) Relation of Hemodynamic Load to Left Ventricular Hypertrophy and Performance in Hypertension. The American Journal of Cardiology, 51, 171-176. https://doi.org/10.1016/S0002-9149(83)80031-9

[5] Sarwar, R. and Cook, S.A. (2009) Genomic Analysis of Left Ventricular Remodeling. Circulation, 120, 437-444. https://doi.org/10.1161/CIRCULATIONAHA.108.797225

[6] Sharma, N., Okere, I.C., Duda, M.K., Chess, D.J., O'Shea, K.M. and Stanley, W.C. (2007) Potential Impact of Carbohydrate and Fat Intake on Pathological Left Ventricular Hypertrophy. Cardiovascular Research, 73, 257-268. https://doi.org/10.1016/j.cardiores.2006.11.007

[7] Gibbs, B.B., Reis, J.P., Schelbert, E.B., Craft, L.L., Sidney, S., Lima, J. and Lewis, C.E. (2014) Sedentary Screen Time and Left Ventricular Structure and Function: The CARDIA Study. Medicine and Science in Sports and Exercise, 46, 276. https://doi.org/10.1249/MSS.0b013e3182a4df33

[8] Aurigemma, G.P., Silver, K.H., Priest, M.A. and Gaasch, W.H. (1995) Geometric Changes Allow Normal Ejection Fraction despite Depressed Myocardial Shortening in Hypertensive Left Ventricular Hypertrophy. Journal of the American College of Cardiology, 26, 195-202. https://doi.org/10.1016/0735-1097(95)00153-Q 
[9] Hill, J.A. and Olson, E.N. (2008) Cardiac Plasticity. New England Journal of Medicine, 358, 1370-1380. https://doi.org/10.1056/NEJMra072139

[10] Tsang, T.S., Barnes, M.E., Gersh, B.J., Takemoto, Y., Rosales, A.G., Bailey, K.R. and Seward, J.B. (2003) Prediction of Risk for First Age-Related Cardiovascular Events in an Elderly Population: The Incremental Value of Echocardiography. Journal of the American College of Cardiology, 42, 1199-1205. https://doi.org/10.1016/S0735-1097(03)00943-4

[11] Mazza, A., Tikhonoff, V., Casiglia, E. and Pessina, A.C. (2005) Predictors of Congestive Heart Failure Mortality in Elderly People from the General Population the Cardiovascular Study in the Elderly (CASTEL). International Heart Journal, 46, 419-431. https://doi.org/10.1536/ihj.46.419

[12] Kannel, W.B., Gordon, T., Castelli, W.P. and Margolis, J.R. (1970) Electrocardiographic Left Ventricular Hypertrophy and Risk of Coronary Heart Disease: The Framingham Study. Annals of Internal Medicine, 72, 813-822.

https://doi.org/10.7326/0003-4819-72-6-813

[13] Levy, D., Garrison, R.J., Savage, D.D., Kannel, W.B. and Castelli, W.P. (1990) Prognostic Implications of Echocardiographically Determined Left Ventricular Mass in the Framingham Heart Study. The New England Journal of Medicine, 322, 1561-1566. https://doi.org/10.1056/NEJM199005313222203

[14] Koren, M.J., Devereux, R.B., Casale, P.N., Savage, D.D. and Laragh, J.H. (1991) Relation of Left Ventricular Mass and Geometry to Morbidity and Mortality in Uncomplicated Essential Hypertension. Annals of Internal Medicine, 114, 345-352. https://doi.org/10.7326/0003-4819-114-5-345

[15] Gottdiener, J.S., Arnold, A.M., Aurigemma, G.P., Polak, J.F., Tracy, R.P., Kitzman, D.W., Gardin, J.M., Rutledge, J.E. and Boineau, R.C. (2000) Predictors of Congestive Heart Failure in the Elderly: The Cardiovascular Health Study. Journal of the American College of Cardiology, 35, 1628-1637.

[16] Aronow, W.S., Ahn, C., Kronzon, I. and Koenigsberg, M. (1991) Congestive Heart Failure, Coronary Events and Atherothrombotic Brain Infarction in Elderly Blacks and Whites with Systemic Hypertension and with and without Echocardiographic and Electrocardiographic Evidence of Left Ventricular Hypertrophy. The American Journal of Cardiology, 67, 295-299. https://doi.org/10.1016/0002-9149(91)90562-Y

[17] Bluemke, D.A., Kronmal, R.A., Lima, J.A., Liu, K., Olson, J., Burke, G.L. and Folsom, A.R. (2008) The Relationship of Left Ventricular Mass and Geometry to Incident Cardiovascular Events: The MESA (Multi-Ethnic Study of Atherosclerosis) Study. Journal of the American College of Cardiology, 52, 2148-2155. https://doi.org/10.1016/j.jacc.2008.09.014

[18] Vakili, B.A., Okin, P.M. and Devereux, R.B. (2001) Prognostic Implications of Left Ventricular Hypertrophy. American Heart Journal, 141, 334-341.

https://doi.org/10.1067/mhj.2001.113218

[19] Kjeldsen, S.E., Dahlöf, B., Devereux, R.B., Julius, S., Aurup, P., Edelman, J., Beevers, G., de Faire, U., Fyhrquist, F., Ibsen, H. and Kristianson, K. (2002) Effects of Losartan on Cardiovascular Morbidity and Mortality in Patients with Isolated Systolic Hypertension and Left Ventricular Hypertrophy: A Losartan Intervention for Endpoint Reduction (LIFE) Substudy. JAMA, 288, 1491-1498. https://doi.org/10.1001/jama.288.12.1491

[20] Swan, L., Birnie, D.H., Padmanabhan, S., Inglis, G., Connell, J.M. and Hillis, W.S. (2003) The Genetic Determination of Left Ventricular Mass in Healthy Adults. European Heart Journal, 24, 577-582. https://doi.org/10.1016/S0195-668X(02)00524-9 
[21] Gardener, H., Rundek, T., Wright, C.B., Gu, Y., Scarmeas, N., Homma, S., Russo, C., Elkind, M.S., Sacco, R.L. and Di Tullio, M.R. (2015) A Mediterranean-Style Diet and Left Ventricular Mass (from the Northern Manhattan Study). The American Journal of Cardiology, 115, 510-514. https://doi.org/10.1016/j.amjcard.2014.11.038

[22] Nguyen, H.T., Bertoni, A.G., Nettleton, J.A., Bluemke, D.A., Levitan, E.B. and Burke, G.L. (2012) DASH Eating Pattern Is Associated with Favorable Left Ventricular Function in the Multi-Ethnic Study of Atherosclerosis. Journal of the American College of Nutrition, 31, 401-407. https://doi.org/10.1080/07315724.2012.10720466

[23] Pitsavos, C.H., Chrysohoou, C., Koutroumbi, M.A., Aggeli, C.O., Kourlaba, G.E., Panagiotakos, D.E., Michaelides, A. and Stefanadis, C.H. (2011) The Impact of Moderate Aerobic Physical Training on Left Ventricular Mass, Exercise Capacity and Blood Pressure Response during Treadmill Testing in Borderline and Mildly Hypertensive Males. Hellenic Journal of Cardiology, 52, 6-14.

[24] De Simone, G. (2005) Left Ventricular Hypertrophy in Blacks and Whites Different Genes or Different Exposure? Hypertension, 46, 23-24. https://doi.org/10.1161/01.HYP.0000169974.90293.4c

[25] Drazner, M.H., Dries, D.L., Peshock, R.M., Cooper, R.S., Klassen, C., Kazi, F., Willett, D. and Victor, R.G. (2005) Left Ventricular Hypertrophy Is More Prevalent in Blacks than Whites in the General Population: The Dallas Heart Study. Hypertension, 46, 124-129. https://doi.org/10.1161/01.HYP.0000169972.96201.8e

[26] Havranek, E.P., Froshaug, D.B., Emserman, C.D., Hanratty, R., Krantz, M.J., Masoudi, F.A., Dickinson, L.M. and Steiner, J.F. (2008) Left Ventricular Hypertrophy and Cardiovascular Mortality by Race and Ethnicity. The American Journal of Medicine, 121, 870-875. https://doi.org/10.1016/j.amjmed.2008.05.034

[27] Lang, R.M., Badano, L.P., Mor-Avi, V., Afilalo, J., Armstrong, A., Ernande, L., Flachskampf, F.A., Foster, E., Goldstein, S.A., Kuznetsova, T. and Lancellotti, P. (2015) Recommendations for Cardiac Chamber Quantification by Echocardiography in Adults: An Update from the American Society of Echocardiography and the European Association of Cardiovascular Imaging. Journal of the American Society of Echocardiography, 28, 1-39. https://doi.org/10.1016/j.echo.2014.10.003

[28] Annis, C., Phanzu, B.K., Sidibe, M., El Hattaoui, M., Dounia, B., Kabangu, J.-R.M. and Longo-Mbenza, B. (2017) The Influence of Ethnicity in the Relationship between Sedentary Screen Time and Left Ventricular Mass: Insights from the MAGSALVAGES. World Journal of Cardiovascular Diseases, 7, 11-23. https://doi.org/10.4236/wjcd.2017.72002

[29] Annis, C., Phanzu, B.K., Moussa, S., El Hattaoui, M., Dounia, B., Kabangu, J.-R.M. and Longo-Mbenza, B. (2017) Lifestyle Changes for Abdominal Obesity Prevention and Encouraging Fruit Consumption May Be Beneficial in Preventing Left Ventricular Hypertrophy in Sub-Saharan African and Maghreb. World Journal of Cardiovascular Diseases, 7, 46-56. https://doi.org/10.4236/wjcd.2017.72005

[30] Danilouchkine, M.G., Westenberg, J.J., de Roos, A., Reiber, J.H. and Lelieveldt, B.P. (2005) Operator Induced Variability in Cardiovascular MR: Left Ventricular Measurements and Their Reproducibility. Journal of Cardiovascular Magnetic Resonance, 7, 447-457.

[31] Kizer, J.R., Arnett, D.K., Bella, J.N., Paranicas, M., Rao, D.C., Province, M.A., Oberman, A., Kitzman, D.W., Hopkins, P.N., Liu, J.E. and Devereux, R.B. (2004) Differences in Left Ventricular Structure between Black and White Hypertensive Adults: The Hypertension Genetic Epidemiology Network Study. Hypertension, 43, 1182-1188. https://doi.org/10.1161/01.HYP.0000128738.94190.9f 
[32] Drazner, M.H. (2004) Left Ventricular Hypertrophy Is More Common in Black than White Hypertensives: Is This News? Hypertension, 43, 1160-1161. https://doi.org/10.1161/01.HYP.0000128740.68851.8a

[33] Chapman, J.N., Mayet, J., Chang, C.L., Foale, R.A., Thom, S.A. and Poulter, N.R. (1999) Ethnic Differences in the Identification of Left Ventricular Hypertrophy in the Hypertensive Patient. American Journal of Hypertension, 12, 437-442. https://doi.org/10.1016/S0895-7061(99)00027-8

[34] Dekkers, C., Treiber, F.A., Kapuku, G., van den Oord, E.J.C.G. and Snieder, H. (2002) Growth of Left Ventricular Mass in African American and European American Youth. Hypertension, 39, 943-951.

[35] Gardin, J.M., Wagenknecht, L.E., Anton-Culver, H., Flack, J., Gidding, S., Kurosaki, T., Wong, N.D. and Manolio, T.A. (1995) Relationship of Cardiovascular Risk Factors to Echocardiographic Left Ventricular Mass in Healthy Young Black and White Adult Men and Women. The CARDIA Study. Circulation, 92, 380-387.

https://doi.org/10.1161/01.CIR.92.3.380

[36] Lorber, R., Gidding, S.S., Daviglus, M.L., Colangelo, L.A., Liu, K. and Gardin, J.M. (2003) Influence of Systolic Blood Pressure and Body Mass Index on Left Ventricular Structure in Healthy African-American and White Young Adults: The CARDIA Study. Journal of the American College of Cardiology, 41, 955-960.

[37] Skelton, T.N., Andrew, M.E., Arnett, D.K., Burchfiel, C.M., Garrison, R.J., Samdarshi, T.E., Taylor, H.A. and Hutchinson, R.G. (2003) Echocardiographic Left Ventricular Mass in African-Americans: The Jackson Cohort of the Atherosclerosis Risk in Communities Study. Echocardiography, 20, 111-120. https://doi.org/10.1046/j.1540-8175.2003.03000.x

\section{Scientific Research Publishing}

\section{Submit or recommend next manuscript to SCIRP and we will provide best} service for you:

Accepting pre-submission inquiries through Email, Facebook, LinkedIn, Twitter, etc. A wide selection of journals (inclusive of 9 subjects, more than 200 journals)

Providing 24-hour high-quality service

User-friendly online submission system

Fair and swift peer-review system

Efficient typesetting and proofreading procedure

Display of the result of downloads and visits, as well as the number of cited articles

Maximum dissemination of your research work

Submit your manuscript at: http://papersubmission.scirp.org/

Or contact wjcd@scirp.org 